\title{
Verdict still out on family health teams
}

$\mathrm{T}$ here is no "MD" in "team" - at least, that's how it used to be. In recent years, however, family physicians have been joining interprofessional health teams. In Ontario alone there are some 200 family health teams serving about three million patients. So how is this new primary care modelling panning out?

The evidence, though spotty, is growing and suggests that interprofessional teams can improve quality of care and other health outcomes in certain environments. But it has also become clear that building an effective team takes a lot more than corralling several health professionals under the same roof and hoping they get along.

"One of the things we understand now is that the transition to effective collaborative teams is much more complex and takes a lot more time than anybody imagined," says Dr. William Hogg, director of research for the department of family medicine at the University of Ottawa in Ontario. "People need to learn about the scope of practice and the skills that different professionals bring to the team. It's not enough just to write it down. You need to work together with different professionals and, over time, work this out. You have to build trusting relationships. This takes years, not months."

Despite the complexities, forming family health teams is a good idea, says Hogg. The evidence base to support this model of care, which is becoming more and more robust, indicates that patients are happier with the care they receive in team-based settings. Doctors also report being more satisfied working in teams than on their own.

"When decision-makers decided to embrace teams in primary care settings, there wasn't much evidence," says Hogg. "As luck would have it, they got it right."

But it's not all good news. Some nonphysician team members have expressed unhappiness, claiming that the dominance of doctors in health care settings makes equality among team members impossible. Tension also arises when

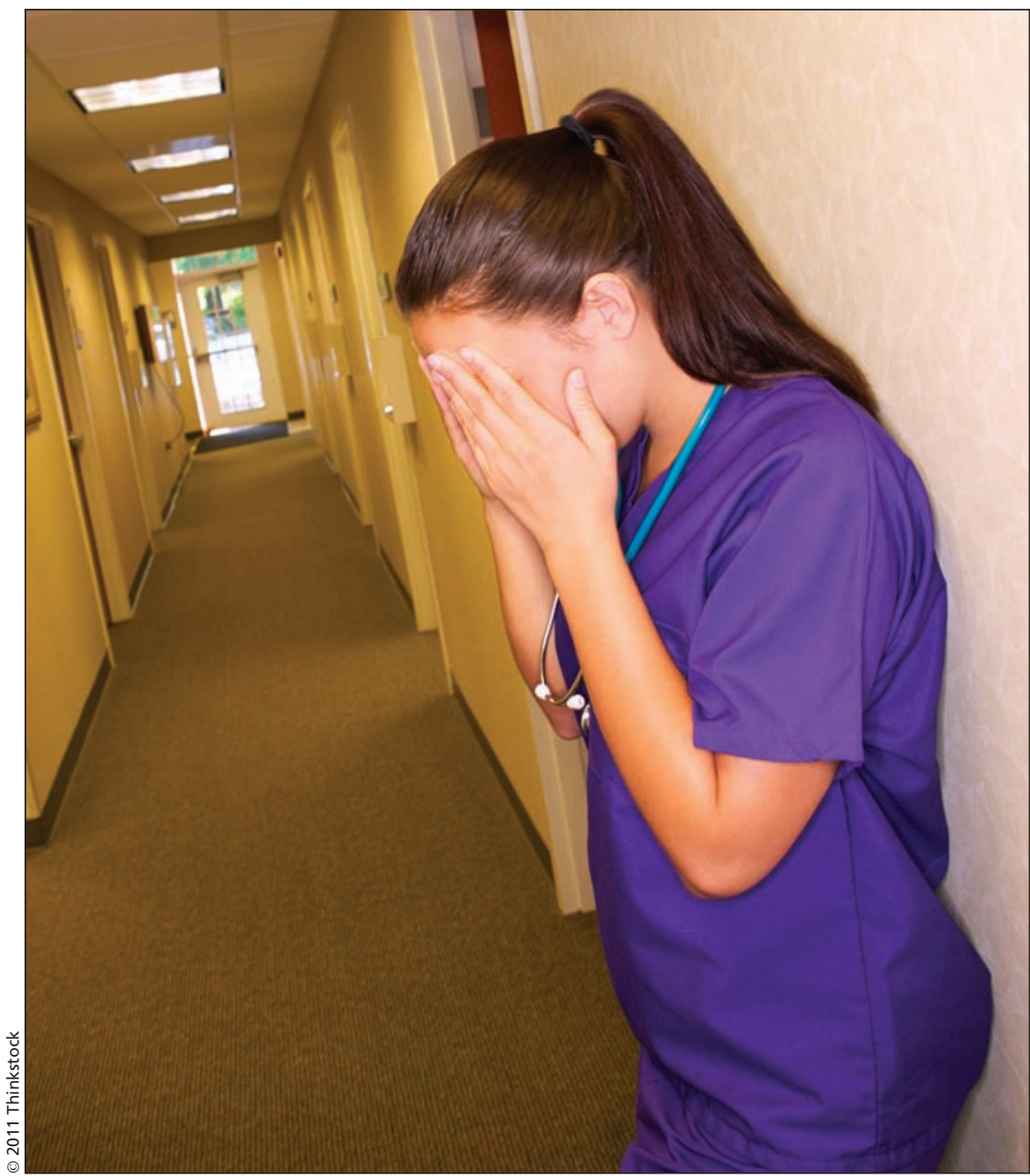

Nurses and other nonphysician members of primary care teams have expressed frustration over the dominance of doctors in health care settings, making equality among family health team members impossible.

there is a significant overlap in skills among members of a health team. In some cases, Hogg says, teams just don't work out and are better off breaking up.

And what about cost-effectiveness? The Ontario government is investing $\$ 300$ million annually in family health teams, and there were hopes that this model would save money, the theory being that some of the services once provided by doctors could be offloaded to lower-paid health professionals, such as nurse practitioners. Unfortunately, there appears to be little quality data on the cost-effectiveness of family health teams.
"The Ministry is unable to qualify, at this time, whether the team-based primary care model is more expensive or cheaper to deliver than the single family doctor practice using more traditional models such as fee-for-service," Andrew Morrison, media relations coordinator for Ontario's Ministry of Health and Long-Term Care, writes in an email. "To respond from an informed position would require lengthy analysis in considering many variables and it is unclear, at this point, whether the data available would meet the quality required for this analysis." 
According to Hogg, the costs of overhead and communications in family health teams may have been underestimated. But even if team-based care turns out to be more expensive, says Hogg, the improvement in quality of care makes the investment worthwhile.

"I'd like to see the government stay the course," says Hogg. "One of the worries I have is that this is very expensive, and it takes a long time to get to the point where it pays a dividend. My concern is that if the government focuses on quick returns, it will grow impatient and move on to some other initiative."

A recent study suggests that not only has this initiative paid dividends, it has been so effective that the United States should consider following Ontario's lead (Ann Fam Med 2011;9:165-71). The Ontario model of team-based primary care may be "North America's largest example of a patient-centred medical home," stated the study, which found several advantages to family health teams, including higher rates of patient satisfaction, as well as higher income and job satisfaction among physicians. Medical students also appear to be more likely to pursue family medicine if they can work on teams.

Overall, though, the research on the effectiveness of primary care teams is inconsistent. In 2007, the Canadian Health Services Research Foundation published a synthesis of available data (www.chsrf.ca/Migrated/PDF/Research Reports/CommissionedResearch/Syn thesisReport_E_rev4_FINAL.pdf). It found that although the amount of highquality research in the area was growing, there were still "large quantities of low- and very low-level evidence."

Furthermore, there are many gaps in the literature. For example, there is limited evidence of how varying team structure affects health outcomes. There is little information on the effects of interprofessional collaboration at the provider and system levels, such as how it affects costs. And though studies have shown positive results in some areas of care - such as mental health care and chronic disease prevention and management - there is limited "moderate- to high-quality evidence" that indicates primary care teams produce better health outcomes in general patient populations.

Hogg and Scott Reeves, associate professor at the University of Toronto's faculty of medicine and editor-in-chief of the Journal of Interprofessional Care, say the Ontario government pushed ahead with family health teams despite the paucity of research on interprofessional collaboration in primary care. "It was an activity undertaken more on enthusiasm than evidence," says Reeves.

Reeves is now helping to provide that evidence, having recently con- tributed to a study on family health teams that highlighted the importance of issues such as leadership, roles and scopes of practice - issues of particular concern to family physicians, whose "identity can be perceived as undergoing a considerable transition at this stage of primary care reform (Can Fam Physician 2010;56:e368-74).

"To have good teamwork, you need clear roles and responsibilities. There has to be regular interaction and feedback on performance, says Reeves, who notes that "tension points" can occur when suggestions are made that someone other than a doctor, such as a nurse, lead a health team - a problem "compounded by hundreds of years of physician and nurse interactions based on one of them being dominant in terms of income and status."

Reeves' study also noted that much of the positive feedback on family health teams stems from perceptions, not empirical evidence. "Such perceptions are important, as they can have implications for satisfaction of the team as well as its morale," the paper states. "Such perceptions, however, require further evaluation to understand their relationships to the realities of accessibility of care and improvement in patient health outcomes." - Roger Collier, CMAJ

CMAJ 2011. DOI:10.1503/cmaj.109-3864

\section{Disparate prescriptions in desperate times}

I deological rants, wish lists, assertions of values, pleas for the disadvantaged and homages to the tenets of free enterprise. Desperate and disaffected souls expressing frustration over inadequate or inequitable care. Privileged and well-heeled professionals disdaining the "lifestyle choices" of the impoverished and uneducated.

The Canadian Medical Association's town hall meetings on health care transformation have been nothing if not a microcosm of Canadian opinion on the merits and values of their health care system and the sixth and final forum in Ottawa, Ontario, was no exception.

The system was lambasted and lauded. It needs money and has too much money. It lacks coherence and oversight, and is rigid and micromanaged.

As vast as the range of diagnoses were the prescriptions, which were alternately thought-provoking, and less so.

Among those offered at the June 7 forum, structured around the topic "Health Care in Canada: Time to Rebuild Medicare," were:

- Reduce the pressure on expensive emergency departments by obligating family doctors and primary care teams to be open for business from 7 am to 10 pm, Monday through Sunday.

- "Punish" Canadians who do not take personal responsibility for their own health and the demands they place on the health care system by smoking and overeating.

- Axe waste such as unnecessary diagnostic imaging.

- Hold doctors to "standards of care" and abandon the fiction that proper treatment can be achieved through a proverbial "seven-minute visit."

- Provide an obstetrician for every village.

- Establish clear and firm guidelines for "rationing" care.

The opinions advanced at all six town hall gatherings have been nothing if not diverse and "passionate," says CMA President Dr. Jeff Turnbull. 